\title{
An Efficient Synthesis of 1, 8-Dioxooctahydroxanthenes Catalysed by Thiourea Dioxide (TUD) in Aqueous Media
}

\author{
PRAVIN S BHALE ${ }^{1,2 *}$, SAKHARAM B DONGARE ${ }^{2}$ and YOGINATH B MULE ${ }^{2}$ \\ ${ }^{1}$ Department of Chemistry, Arts, Science \& Commerce College, Naldurg, Tq-Tuljapur, \\ Dist.- Osmanabad- 413602(Maharashtra), India \\ ${ }^{2}$ Medicinal Chemistry Research laboratory, School of Chemical Sciences, Solapur \\ University, Solapur-413 255(Maharashtra), India \\ bhale.ps@gmail.com
}

Received 13 October 2014 / Accepted 8 November 2014

\begin{abstract}
A simple and highly efficient protocol for the synthesis of biologically active 1,8-dioxooctahydroxanthenes from various aromatic aldehydes with dimedone by using thiourea dioxide (TUD) as catalyst in aqueous media is reported. This protocol gives wide range of xanthene derivatives with high yield.
\end{abstract}

Keywords: 1,8-Dioxooctahydroxanthenes, Dimedone, Aromatic aldehydes, Thiourea dioxide, TUD

\section{Introduction}

Xanthene and their derivatives are an important family of organic compounds because they have wide range of biological and pharmaceutical properties such as antibacterial ${ }^{1}$, antiviral $^{2}$, anti-inflammatory ${ }^{3}$, anti-depressants and antimalarial agents ${ }^{4}$. Also, they are as structural unit in a number of natural products ${ }^{5}$ and santalin pigments isolated from a number of plant species are major sources for xanthenes ${ }^{6}$. Furthermore, these compounds are utilized in industries as leuco-dye $\mathrm{e}^{7}$, in laser technology ${ }^{8}$, as $\mathrm{pH}$ sensitive fluorescent materials for the visualization of biomolecular assemblies ${ }^{9}$ and used in photodynamic therapy ${ }^{10}$. Recently, xanthenes have been used as rigid carbon skeletons for the construction of new chiral bidentate phosphine ligands with potential applications in catalytic processes ${ }^{11}$.

Even though, various methods have been reported for preparation of xanthenes and substituted xanthenes, the classical method for the synthesis of 1,8-dioxo-octahydro xanthenes involves the condensation of appropriate active methylene carbonyl compounds with aldehydes ${ }^{12}$. For this purpose, two molecules of dimedone (5,5-dimethyl-1,3- cyclohexane dione) reacts with various aromatic aldehydes ${ }^{13}$, by using of different Lewis acid catalysts such as triethylbenzyl ammonium chloride ${ }^{14}$, p-dodecyl benzenesulfonic acid ${ }^{15}$, diammonium hydrogen phosphate under various conditions ${ }^{16}$, sulfonic acid under ultrasonic irradiation ${ }^{17}$, ionic liquids ${ }^{18}$, Amberlyst- $15^{19}, \mathrm{NaHSO}_{4}-\mathrm{SiO}_{2}$ or silica chloride ${ }^{20}$, phosphomolybdic acid 
supported on silica gel ${ }^{21}$, nanosized MCM-41- $\mathrm{SO}_{3} \mathrm{H}$ under ultrasonic irradiation ${ }^{22}$, sulfonic acid on silica gel $^{23}$, Dowex-50W ion exchange resin under solvent-free conditions ${ }^{24}$, $\mathrm{HClO}_{4}-\mathrm{SiO}_{2}, \mathrm{ZnO}^{25}$ and $\mathrm{ZnO}$ acetyl chloride ${ }^{26}$ and heteropoly acid supported MCM- $41^{27}$. Each of these methods have their own advantages but also suffer from one or more disadvantages such as prolonged reaction time, tedious work-up processes, low yield, lack of easy availability/preparation of starting materials and hazardous reaction conditions.

Thiourea dioxide (TUD) ${ }^{28}$ easily prepared by the oxidation of thiourea with hydrogen peroxide is highly stable and possesses the ability to activate organic substrates through hydrogen bonding. Owing to the presence of two extra oxygen atoms it forms strong hydrogen bonding and can provide higher activation than the corresponding thiourea. In addition, thiourea dioxide is insoluble in common organic solvents and therefore can easily be recovered at the end of the reaction for its reuse. Despite its high potential, the use of thiourea dioxide as organocatalyst for organic reactions is not much reported in the literature ${ }^{29}$.

In continuation of our interest on synthesis of heterocyclic compounds, we report here a new, green and highly efficient method for the synthesis of 1,8-dioxooctahydroxanthenes via the condensation of dimedone with aldehydes using TUD as catalyst in aqueous media at 50$60{ }^{\circ} \mathrm{C}$ (Scheme 1).

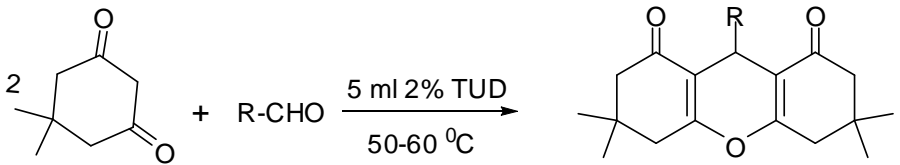

Scheme 1. Synthesis of 1,8-dioxo-octahydroxanthenes using TUD as catalyst

\section{Experimental}

All chemicals were purchased from Merck or Fluka Chemical Companies and they were used as received. All compounds are known and their structures were identified by comparing their melting points and ${ }^{1} \mathrm{H}$ and ${ }^{13} \mathrm{C}$ NMR data with those reported in the literature. The ${ }^{1} \mathrm{H}$ NMR (500 MHz, $400 \mathrm{MHz}$ ) and ${ }^{13} \mathrm{C}$ NMR $(125 \mathrm{MHz}, 100 \mathrm{MHz})$ spectra were recorded on a Bruker Avance DPX-250, FT-NMR spectrometer ( $\delta$ in ppm). Tetramethylsailane (TMS) was used as internal standard. The abbreviations used for NMR signals are: $\mathrm{s}=$ singlet, $\mathrm{d}=$ doublet, $\mathrm{t}=$ triplet, $\mathrm{q}=$ quartet, and $\mathrm{m}=$ multiplet. Melting points were recorded on a Büchi B-545 apparatus in open capillary tubes and are uncorrected.

General procedure for the preparation of 1,8-dioxo-octahydroxanthenes using Thiourea dioxide as catalyst

A mixture of dimedone (2 mmol), aromatic aldehyde $(1 \mathrm{mmol})$ and $5 \mathrm{~mL}$ of $2 \%$ thiourea dioxide(TUD) aqueous solution in a round-bottomed flask connected to a reflux condenser, was heated and stirred in an oil-bath $\left(50-60^{\circ} \mathrm{C}\right)$ for appropriate time shown in Table 2 . After completion the reaction as monitored by TLC, cool the reaction mass and filter the obtained solid and recrystallized in ethanol to afford the pure products.

\section{Representative spectral data of the products}

\section{3,3,6,6-Tetramethyl-9(phenyl)-1,8-dioxo-octahydroxanthene (Table 2, Entry 1)}

${ }^{1} \mathrm{H} \mathrm{NMR}\left(\mathrm{CDCl}_{3}, 500 \mathrm{MHz}\right): \delta 0.90$ (s, 6H), 1.04 (s, 6H), 2.09 (d, J = $\left.16.1 \mathrm{~Hz}, 2 \mathrm{H}\right), 2.27$ (d, $\mathrm{J}=16.2 \mathrm{~Hz}, 2 \mathrm{H}), 2.53(\mathrm{~d}, \mathrm{~J}=17.1 \mathrm{~Hz}, 2 \mathrm{H}), 2.58(\mathrm{~d}, \mathrm{~J}=17.7 \mathrm{~Hz}, 2 \mathrm{H}), 4.53(\mathrm{~s}, 1 \mathrm{H}), 7.10$ (t, J $=7.0 \mathrm{~Hz}, 1 \mathrm{H}), 7.18(\mathrm{~d}, \mathrm{~J}=7.0 \mathrm{~Hz}, 2 \mathrm{H}), 7.21(\mathrm{t}, \mathrm{J}=7.20 \mathrm{~Hz}, 2 \mathrm{H}) ;{ }^{13} \mathrm{C} \mathrm{NMR}\left(\mathrm{CDCl}_{3}, 125\right.$ MHz): 27.7, 29.6, 32.3, 32.6, 41.3, 51.2, 116.1, 126.8, 128.4, 128.8, 144.5, 162.7, 196.8. 
3,3,6,6-Tetramethyl-9(4-chloro-Phenyl)-1,8-dioxo-octahydroxanthene (Table 2, Entry 2)

${ }^{1} \mathrm{H} \mathrm{NMR}\left(\mathrm{CDCl}_{3}, 500 \mathrm{MHz}\right): \delta 0.90$ (s, 6H), 1.04 (s, 6H), 2.09 (d, J = $\left.16.1 \mathrm{~Hz}, 2 \mathrm{H}\right), 2.27$ (d, $\mathrm{J}=16.1 \mathrm{~Hz}, 2 \mathrm{H}), 2.52$ (d, 2H), 2.57 (d, J = 17.6 Hz, 2H), 4.51 (s, 1H), 7.19 (d, J = 8.3 Hz,

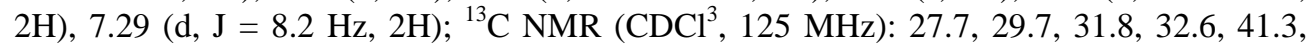
51.1, 115.6, 128.6, 130.2, 132.4, 143.1, 162.8, 196.7.

3,3,6,6-Tetramethyl-9(3-nitro-Phenyl)-1,8-dioxo-octahydroxanthene (Table 2, Entry 6) ${ }^{1} \mathrm{H} \mathrm{NMR}\left(\mathrm{CDCl}_{3}, 500 \mathrm{MHz}\right): \delta 0.91$ (s, 6H), 1.04 (s, 6H), 2.11 (d, J = $\left.16.1 \mathrm{~Hz}, 2 \mathrm{H}\right), 2.29$ (d, $\mathrm{J}=16.1 \mathrm{~Hz}, 2 \mathrm{H}), 2.57$ (d, J = 17.9 Hz, 2H), 2.60 (d, J = 17.9 Hz, 2H), 4.65 (s, 1H), 7.56 (t, J $=7.7 \mathrm{~Hz}, 1 \mathrm{H}), 7.66(\mathrm{~d}, \mathrm{~J}=7.6 \mathrm{~Hz}, 1 \mathrm{H}), 8.00(\mathrm{~d}, 2 \mathrm{H}) ;{ }^{13} \mathrm{C} \mathrm{NMR}\left(\mathrm{CDCl}_{3}, 125 \mathrm{MHz}\right): 27.2$, 29.6, 32.0, 32.7, 50.9, 56.6, 60.7, 106.3, 115.1, 136.8, 140.7, 153.2, 163.9, 197.0

\section{Results and Discussion}

Initially, we studied effect of amount of the catalysts on the reaction of dimedone (2 mmol) with benzaldehyde $(1 \mathrm{mmol})$ at $55-60{ }^{\circ} \mathrm{C}$. The results are summarized in Table 1 . As it can be seen in Table 1, the best amounts of TUD aqueous solution was $2 \%$.

Table 1. Synthesis of 3,3,6,6-Tetramethyl-9(phenyl)-1,8-dioxo-octahydroxanthene

\begin{tabular}{cccc}
\hline S. No. & \% of TUD aqueous solution & Time in Min & Yield \% \\
\hline 1 & 10 & 45 & 92 \\
2 & 5 & 45 & 92 \\
3 & 2 & 45 & 96 \\
4 & 1 & 70 & 80 \\
\hline
\end{tabular}

After optimization of the reaction conditions, dimedone was reacted with different types of aldehydes (including aromatic aldehydes possessing electron-releasing substituents, electron-withdrawing substituents and halogens on their aromatic rings) in the presence of the thiourea dioxide as catalysts. The results are displayed in Table 2. As it is shown in Table 2, all reactions were completed within 35-50 min and the desired products were obtained in good to excellent yields (82-97\%). Thus, our method is highly efficient and general.

Table 2. Synthesis of 1,8-dioxo-octahydroxanthenes using TUD as catalyst

\begin{tabular}{clccc}
\hline Entry & \multicolumn{1}{c}{$\mathrm{R}$} & Time in Min & Yield $^{\mathrm{a}} \%$ & M.P. ${ }^{\circ} \mathrm{C}$ \\
\hline 1 & $\mathrm{C}_{6} \mathrm{H}_{5}$ & 45 & 96 & $200-202$ \\
2 & $p-\mathrm{ClC}_{6} \mathrm{H}_{4}$ & 35 & 97 & $230-232$ \\
3 & $m-\mathrm{ClC}_{6} \mathrm{H}_{4}$ & 35 & 90 & $184-186$ \\
4 & $o-\mathrm{ClC}_{6} \mathrm{H}_{4}$ & 40 & 91 & $224-226$ \\
5 & $p-\mathrm{NO}_{2} \mathrm{C}_{6} \mathrm{H}_{4}$ & 40 & 97 & $222-224$ \\
6 & $m-\mathrm{NO}_{2} \mathrm{C}_{6} \mathrm{H}_{4}$ & 30 & 94 & $162-164$ \\
7 & $o-\mathrm{NO}_{2} \mathrm{C}_{6} \mathrm{H}_{4}$ & 50 & 88 & $250-252$ \\
8 & $p-\mathrm{Br}_{6} \mathrm{H}_{4}$ & 40 & 92 & $240-242$ \\
9 & $o-\mathrm{BrC}_{6} \mathrm{H}_{4}$ & 40 & 83 & $226-228$ \\
10 & $p-\mathrm{CNC}_{6} \mathrm{H}_{4}$ & 45 & 82 & $218-220$ \\
11 & $p-\mathrm{CH}_{3} \mathrm{C}_{6} \mathrm{H}_{4}$ & 40 & 94 & $214-216$ \\
12 & $m-\mathrm{CH}_{3} \mathrm{C}_{6} \mathrm{H}_{4}$ & 35 & 94 & $208-210$ \\
13 & $o-\mathrm{CH}_{3} \mathrm{C}_{6} \mathrm{H}_{4}$ & 50 & 84 & $210-212$ \\
14 & $p-\mathrm{CH}_{3} \mathrm{OC}_{6} \mathrm{H}_{4}$ & 45 & 89 & $242-244$ \\
15 & $m-\mathrm{CH}_{3} \mathrm{OC}_{6} \mathrm{H}_{4}$ & 50 & 85 & $160-162$ \\
\hline
\end{tabular}

${ }^{a}$ Isolated yields 


\section{Conclusion}

We have developed a new method for the synthesis of 1,8-dioxoocta-hydroxanthenes using TUD in aqueous media as catalyst. The simple experimental and work-up procedure, high yields, relatively short reaction times, application of inexpensive catalyst and compliance with the green chemistry protocols are the advantages of the present method.

\section{Acknowledgment}

The authors are thankful to Principal, ASC College, Naldurg, Dist- Osmanabad, Maharashtra, India for providing laboratory facilities.

\section{References}

1. Hideo T, Tokkyo Koho J P 56005480, 1981, Chem Abstr., 1981, 95, 80922b, Jpn.

2. Lambert R W, Martin J A, Merrett J H, Parkes K E B and Thomas G J, PCT Int Appl.,WO9706178, 1997, Chem Abstr., 1997, 126, p212377y.

3. Poupelin J P, Saint-Rut G, Fussard-Blanpin O, Narcisse G, Uchida-Ernouf G and Lakroix R, Eur J Med Chem., 1978, 13, 67-71.

4. Chibale K, Visser M, Schalkwyk D V, Smith P J, Saravanamuthu A and Fairlamb A H, Tetrahedron, 2003, 59(13), 2289-2296; DOI:10.1016/S0040-4020(03)00240-0

5. (a) Hatakeyma S, Ochi N, Numata H and Takano S, J Chem Soc Chem Commun., 1988, 1202-1204; DOI:10.1039/C39880001202 (b) Cingolant G, Fulvio G and Pigini M, J Med Chem., 1969, 12, 531-532; DOI:10.1021/jm00303a616

6. (a) Arnone A, Merlini L and Nasini G, Tetrahedron Lett., 1972, 13(33), 3503-3506; DOI:10.1016/S0040-4039(01)94083-3 (b) Ravindranath B and Sheshadri T R, Phytochemistry, 1973, 12(11), 2781-2788; DOI:10.1016/0031-9422(73)85099-X (c) Kinjo J, Uemura H, Nohara T, Yamashita M, Marubayashi N and Yoshihira K, Tetrahedron Lett., 1995, 36(31), 5599-5602; DOI:10.1016/0040-4039(95)01071-O

7. Banerjee A and Mukherjee A K, Stain Technol., 1981, 56(2), 83-85.

8. (a) Menchen S M, Benson S C, Lam J Y L, Zhen W, Sun D, Rosenblum B B, Khan S H and Taing M, U.S. Patent, US6583168, 2003, Chem Abstr., 2003, 139, p54287f;

(b) Sirkecioglu O, Tulinli N and Akar A, J Chem Res (S), 1995, 502-506.

9. (a) Bekaert A, Andrieux J and Plat M, Tetrahedron Lett., 1992, 33(20), 2805-2806; DOI:10.1016/S0040-4039(00)78863-0 (b) Sarma R J and Baruah J B, Dyes Pigm., 2005, 64(1), 91-92; DOI:10.1016/j.dyepig.2004.03.010 (c) Buehler C A, Cooper D E and Scrudder E O, J Org Chem., 1943, 8(4), 316-319; DOI:10.1021/jo01192a003 (d) Knight C G and Stephens T, Biochem J., 1989, 258(3), 683-687.

10. (a) Ion R M, Frackowiak D, Planner A and Wiktorowicz K, Acta Biochim Pol., 1998, 45(3), 833-845; (b) Ion R M, Prog Catal., 1997, 6, 55.

11. (a) Hamada Y, Matsuura F, Oku M, Hatano K and Shioiri T, Tetrahedron Lett., 1997, 38(52), 8961-8964; DOI:10.1016/S0040-4039(97)10363-X (b) Hillebrand S, Bruckmann J, Kruger C and Haenel M W, Tetrahedron Lett., 1995, 36(1), 75-78; DOI:10.1016/0040-4039(94)02206-Q (c) Malaise G, Barloy L and Osborn J A, Tetrahedron Lett., 2001, 42(42), 7417-7419; DOI:10.1016/S0040-4039(01)01588-X

12. Kuthan J, Sebek P and Bohm S, Advances in Heterocyclic Chemistry; Academic Press lnc: New York, 1995,62, 19.

13. (a) Horning E C and Horning M G, J Org Chem., 1946, 11(1), 95-99; DOI:10.1021/jo01171a014 (b) Tu S J, Zhou J F, Lu Z S, Deng X, Shi D Q and Wang S H, Synth Commun., 2002, 32(19), 3063-3067; DOI:10.1081/SCC-120012999 
(c) Jin, T S, Zhang J S, Wang A Q and Li T S, Synth Commun., 2005, 35(17), 23392345; DOI:10.1080/00397910500187282

14. Wang X S, Shi D Q, Li Y L, Chen H, Wei X Y and Zong Z M, Synth Commun., 2005, 35(1), 97-104; DOI:10.1081/SCC-200046510

15. Jin T S, Zhang J S, Xiao J C, Wang A Q and Li T S, Synlett., 2004, 866-870; DOI:10.1055/s-2004-820022

16. Darvish F, Balalaei S, Chadegani F and Salehi P, Synth Commun., 2007, 37, 10591066; DOI:10.1080/00397910701196520

17. Jin T S, Zhang J S, Wang A Q and Li T S, Ultrason Sonochem., 2006, 13(3), 220224; DOI:10.1016/j.ultsonch.2005.04.002

18. Dabiri M, Baghbanzadeh M and Arzroomchilar E, Catal Commun., 2008, 9(5), 939942; DOI:10.1016/j.catcom.2007.09.023

19. Das B, Thirupathi P, Mahender I, Reddy V S and Rao Y K, J Mol Catal A Chem., 2006, 247(1-2), 233-239; DOI:10.1016/j.molcata.2005.11.048

20. Das B, Thirupathi P, Mahender I, Reddy K R, Ravikanth B and Nagarapu L, Catal Commun., 2007, 8(3), 535-538; DOI:10.1016/j.catcom.2006.02.023

21. Srihari P, Mandal S S, Reddy J S S, Srinivasa Rao R and Yadav J S, Chin Chem Lett., 2008, 19(7), 771-774;DOI:10.1016/j.cclet.2008.05.005

22. Rostamizadeh S, Amani A M, Mahdavinia G H, Amiri G and Sepehrian H, Ultrason Sonochem., 2010, 17(12), 306-309; DOI:10.1016/j.ultsonch.2009.10.004

23. Mahdavi G H, Bigdeli M A and Saeidi Hayeniaz Y, Chin Chem Lett., 2009, 20(5), 539-541; DOI:10.1016/j.cclet.2008.12.026

24. Imani Shakibaei G, Mirzaei P and Bazgir A, Appl Catal A: General, 2007, 325(1), 188-192; DOI:10.1016/j.apcata.2007.03.008

25. Kantevari S, Bantu R and Nagarapu L, J Mol Catal A: Chem., 2007, 269(1-2), 53-57; DOI:10.1016/j.molcata.2006.12.039

26. Maghsoodlou M T, Habibi-Khorassani S M, Shahkarami Z, Maleki N and Rostamizadeh M, Chin Chem Lett., 2010, 21(6), 686-689; DOI:10.1016/j.cclet.2010.02.005

27. Karthikeyan G and Pandurangan A, J Mol Catal A: Chem., 2009, 311(1-2), 36-45; DOI:10.1016/j.molcata.2009.06.020

28. Ohura O and Fujimoto O, U.S. Patent 4, 233,238, 1980.

29. S.Verma, S. L. Jain and B. Sain, Tetrahedron Lett., 2010, 51(52), 6897-6900; DOI:10.1016/j.tetlet.2010.10.124 